\title{
Fake Science: uma análise de vídeos divulgados sobre a pandemia
}

Fake Science: an analysis of videos released about the pandemic

Marcia Borin da Cunha ${ }^{1}$

Vanessa Ron Jen Chang ${ }^{2}$

\section{Resumo}

Notícias e informações falsas sobre variados assuntos não é característica do momento atual, mas a forma de disseminação destas informações é que tem sido alterada nos últimos anos. Além da disseminação, também é possível perceber que o modo de recepção das mensagens tem sido diferente. Neste último caso, estudos apontam para o que se pode denominar de "Era da Pós-verdade". Neste contexto amplo e complexo aparecem as Fake News, e quando se trata de assuntos de ciências podemos chamar de Fake Science, sendo este um tema de interesse para discussão de propostas de Letramento Informacional e Midiático (LIM) para escola. Neste artigo apresentamos a análise e reflexão sobre vídeos compartilhados em usuários do aplicativo WhatsApp, quando o assunto é a COVID-19. As análises dos vídeos nos levam a caracterização das mensagens e o estabelecimento de indicadores que podem ser utilizados para atividades em sala de aula para o LIM.

Palavras chave: Fake News, pseudociência, letramento informacional e midiático, vídeos, pandemia.

\section{Abstract}

Fake news and misleading information on various subjects is not characteristic of nowadays, but the way in which this information is disseminated has changed in recent years. In addition to dissemination of information, it is also possible to see that the way messages are received has been different. In the latter case, studies point to what can be called the "Posttruth era". In this broad context and complex environment, Fake News appears, and when it comes to science subjects, we can call it Fake Science, which is a topic of interest for proposal discussion for Informational and Media Literacy for schools. In this article we present the analysis and reflection on videos shared by WhatsApp application users, when the subject is COVID-19. The analysis of the videos leads us to the characterization of the messages and the establishment of indicators that can be used for classroom activities for Informational and Media Literacy.

Keywords: misinformation, pseudoscience, Informational and Media Literacy, videos, pandemic.

\footnotetext{
${ }^{1}$ Universidade Estadual do Oeste do Paraná, Unioeste | marcia.cunha@unioeste.brm

${ }^{2}$ Universidade Estadual do Oeste do Paraná, Unioeste | vanessajen@hotmail.com
} 


\title{
Introdução
}

\author{
A falsidade voará, por assim dizer, nas asas do vento, e \\ leve seus contos a todos os cantos da terra; enquanto a verdade demora \\ atrás; seus passos, embora seguros, são lentos e solenes, e ela \\ não tem vigor nem atividade suficiente para perseguir e superar \\ seu inimigo. \\ Thomas Francklin, Sermons on Various Subjects, $1787^{3}$
}

A tecnologia, ao longo dos anos, por meio do uso de celulares do tipo smartphone, transformou-se em um veículo de informação e compartilhamento de mensagens, nem sempre desejáveis. A partir disso, as Fakes News ganham força com a disseminação de notícias falsas e, assim, sem mesmo percebemos, estamos vivendo na era de Pós-verdade, em que as emoções e crenças são mais significativas do que o próprio fato. Segundo D'Ancona (2018, p. 19), "A racionalidade está ameaçada pela emoção; a diversidade, pelo nativismo; a liberdade, por um movimento rumo à autocracia [...] A ciência é tratada com suspeição e, às vezes, franco desprezo."

Quando nos referimos às notícias falsas de conteúdo científico, podemos denominar de "Fake Science", na qual as informações que chegam até o público, por meio de grupos e redes sociais, acabam promovendo uma "cultura científica" ao avesso, pois a ciência e a tecnologia são apresentadas de forma equivocada, tanto no que se refere ao seu conteúdo, quanto às percepções de ciência, como é o caso de uma "ciência simples" para a solução de problemas complexos.

Para compreender melhor sobre o Fake News e Fake Science é necessário buscar na literatura em diferentes autores alguns conceitos envolvidos para compreensão do tema. Atualmente é possível encontrar livros publicados sobre o assunto como: "Pós-Verdade: A nova Guerra contra os fatos em termos de Fake News" (D'ANCONA, 2018); "Ciência Picareta" (GOLDACRE, 2013); "Ciência e pseudociência: por que acreditamos apenas naquilo em que queremos acreditar" (PILATI, 2018); "O mundo assombrado pelos demônios: a ciência vista como uma vela no escuro" (SAGAN, 2006), dentre outros.

Diante deste contexto geral, esta pesquisa teve como foco selecionar algumas Fake Science em forma de vídeo e analisá-las, na tentativa de estabelecer alguns padrões, no que se refere à sua composição enquanto gênero discursivo. Esta seleção pode ser feita tanto em informações escritas, quanto em vídeos (por meio da transcrição). Contudo, nesse artigo apresentamos a análise de quatro vídeos relacionados ao tema da pandemia e considerados como Fake Science. Nesta perspectiva nossos objetivos situam-se em estudar temas, conceitos e assuntos relacionados com a ideia de notícias falsas em ciências; comparar vídeos, estabelecer padrões das informações falsas de modo a compreender os fatores que fazem o público acreditar em uma informação deste tipo.

\footnotetext{
${ }^{3}$ Andrew David Thaler; David Shiffman. Tradução nossa. Disponível em: http://www.blackbeardbiologic.com/wpcontent/uploads/2019/06/Thaler_2015-Fish-Tales.pdf.
} 
Todo este estudo nos leva a considerar que é importante trazer para a escola tais discussões na perspectiva do letramento crítico midiático, que leve à formação crítica dos jovens.

A definição geral de letramento está associada à capacidade do sujeito em ler e escrever a partir do reconhecimento de letras e palavras e sua interpretação em um conjunto de enunciados e inclui a habilidade de identificar os diferentes tipos de mídia, interpretando as informações e mensagens presentes nas mídias. Neste sentido é mais do que apenas ler e interpretar, que são elementos presentes em um texto qualquer, mas também inclui o desenvolvimento de habilidades de interpretação de memes, vídeos virais, games e propagandas como conteúdo duvidoso. Segundo Bittencourt et.al. (2016, p. 3) "Não basta saber ler e escrever, para ser letrado é necessário saber interpretar o que se lê questionar e investigar, ser capaz de ir além do que está escrito, para que assim haja um crescimento intelectual do sujeito, tornando-o cada vez mais crítico.".

Neste contexto, as notícias falsas devem fazer parte de atividades de letramento midiático, fazendo parte das aulas de Ciências na escola, nos diversos níveis de ensino.

Perceber e distinguir o verdadeiro do falso é tarefa importante e necessária na sociedade atual. Tarefa esta nem sempre fácil, pois algumas notícias podem aparecer em formato bastante semelhante às notícias verdadeiras, inclusive inserindo especialistas como entrevistados para dar credibilidade à informação. Neste formato, estão as correntes de WhatsApp com mensagens alarmistas e pedidos para seu compartilhamento, propagandas de medicamentos milagrosos que melhoram a saúde e a estética, notificação de concursos que já aconteceram ou que nunca irão acontecer, regras novas de órgãos governamentais, ou sátiras. Neste último caso, os usuários de aplicativos têm disseminado sátiras de alguns sites que tem como objetivo o entretenimento, utilizando a sátira como se fosse uma notícia verdadeira. As sátiras são uma espécie de paródia de conteúdos jornalísticos, ou seja, se inspiram no fato para produzir outro gênero discursivo.

Diante disso, conteúdos sobre assuntos de Ciência e Tecnologia têm sido propagados com grande frequência e, para tanto, é necessário que se promovam ações no ensino formal sobre letramento midiático em ciências, denominado também de Letramento Informacional e Midiático (LIM). A importância do LIM não vale apenas para estudantes do ensino médio, mas para acadêmicos e professores, assim como pontuam Ribeiro e Gasque (2015):

O papel da escola, como espaço de formação de cidadãos, deve abranger a importância do Letramento Informacional e Midiático (LIM) no ambiente acadêmico, tanto para os estudantes quanto para os professores, pois estes últimos são personagens-chave para o desenvolvimento do LIM tanto dentro quanto fora de sala de aula. (RIBEIRO; GASQUE, 2015, p. 205).

No que se refere a este projeto de pesquisa, nossa intenção foi realizar um levantamento de informações falsas sobre ciência e tecnologia e analisá-las no sentido de elencar elementos que pudessem estar presentes nestas informações, e que nos levem à identificação delas por meio da sua caracterização. Consideramos que identificar e caracterizar padrões no discurso de uma informação falsa nos encaminha à proposição de atividades didáticas em prol de um Letramento Informacional e Midiático em ciências. 


\section{Fake News e Fake Science}

No ano de 2016, segundo D'Ancona, o Oxford Dictionary escolheu "Pós-verdade" como a palavra do ano, definindo esta como "[...] circunstâncias em que os fatos objetivos são menos influentes em formar opinião pública do que os apelos à emoção e à crença pessoal." (D'ANCONA, 2018, p. 20). Para este autor, esse termo já tinha sido usado no ano de 1992 na revista The Nation em um artigo de um escritor sérvio-norte-americano. Mas, Pós-verdade e, mais recentemente, Fake News são expressões que vêm ganhando destaque, especialmente em assuntos ligados à política. Este fato se deve ao acesso livre de usuários de redes de informação como Facebook e WhatsApp.

Notícias falsas (que se tornam verdade) sobre diversos assuntos têm sido a pauta de discussão em grupos nas redes sociais. É por meio do compartilhamento das informações que uma notícia acaba sendo direcionada há milhares de pessoas, tornando-se uma "verdade". As Fake News são terreno fértil para a Pós-verdade, esta última tem como princípio relacionar uma situação em que informações falsas, com forte apelo emocional e crenças pessoais, se sobrepõem a informações verdadeiras com o objetivo de mudar a opinião pública.

De modo geral podemos dizer que uma Fake News tem uma parte "comprovável" da mensagem ou de conhecimento do público em geral, mas outra parte, verdadeira, é omitida. Para Monteiro, et al (2018, s.p) "A insinuação, a pressuposição e o subentendimento, a falta de contexto e a inversão da relevância são agentes fundamentais para a difusão de informações falsas e tendenciosas."

As Fake News divulgam (erroneamente) informações e notícias sobre diferentes assuntos, dentre eles, a Ciência. Para tal tipo de informação (errada ou deturpada) sobre Ciência denominaremos aqui de Fake Science, considerando uma aproximação ao termo genérico e amplamente conhecido para Fake News. A definição para Fake Science, guarda características da anteriormente denominada "pseudociência" como "[...] algo que quer se passar por ciência sem ter o seu estatuto". (SCHULZ, 2018, s.p). Segundo este mesmo autor "[...] existem critérios para diferenciar a pseudociência da ciência" (SCHULZ, 2018, s.p), quando observamos que o objetivo da ciência é produzir verdades discutíveis, enquanto as verdades indiscutíveis são pós-verdadeiras.

Para Hopf e colaboradores, em publicação na The Royal Society:

Na era da 'pós-verdade', o engano é comum em todos os níveis da vida contemporânea. A falsificação afeta a ciência e as informações sociais e as duas se tornaram altamente interativas globalmente, minando a confiança na ciência e a capacidade dos indivíduos e da sociedade de fazer escolhas baseadas em evidências, incluindo questões de vida ou morte" (HOPF et al., s.p, 2019, tradução nossa).

Neste sentido, a Ciência é atingida porque conta com informações de interesse público, mas também por ter um estatuto de credibilidade frente à população. Assim, notícias sobre Ciência são amplamente disseminadas e passam a formar grupos que não só compartilham as mensagens como também tomam decisões com base nestas informações. Como exemplo, podemos citar, o movimento antivacina que tem adeptos no mundo todo. Esse movimento se instituiu a partir de notícias falsas sobre vacinas e tem influenciado diretamente as pessoas, inclusive sobre decisões de vacinar ou não seus filhos. O problema 
é tão grave que doenças já consideradas controladas voltaram a fazer parte do contexto atual, um exemplo, o sarampo.

Outras notícias como a teoria de que o homem jamais pisou na Lua tem sido imensamente compartilhada por usuários de Web e redes sociais e tornam-se verdades a ponto das pessoas a considerarem verdadeira e duvidarem de imagens registradas na época, alegando que tais imagens foram produzidas recentemente, ou seja, foram manipuladas. Outro exemplo são as notícias sobre a "teoria" da Terra plana, ou que moléculas de água respondem à sentimentos alterando a sua estrutura na forma de cristais. Esses e outros exemplos nos dão indicativos para refletir sobre o papel da educação na formação crítica das pessoas e do LIM.

Ancorada na ideia de educação para a formação crítica, destacamos a importância do tratamento, nas aulas de Ciências, de Fake Science, pois estas deturpam informações provenientes da ciência, para as quais existem comprovações científicas, interferindo em percepções e ideias de conteúdo científico e sobre a Ciência.

Destacamos que o compartilhamento de informações falsas atingiu altos índices a partir do final do ano de 2019, em função da pandemia causada pelo vírus SARS-Cov-19. Como um problema global e sem solução a curto prazo, mensagens para cura ou profilaxia têm sido amplamente apresentadas e compartilhadas nas redes sociais e em meios de comunicação direta como é o caso do WhatsApp. Tanta desinformação só tende a agravar a situação de controle da pandemia, levando o Brasil a índices de contágio e mortes alarmantes. De acordo com a notícia de site UOL (2020):

\begin{abstract}
Uma pesquisa da Avaaz aponta que sete em cada dez internautas brasileiros, cerca de 100 milhões de pessoas, acreditam em ao menos uma notícia falsa a respeito da pandemia de coronavírus. Segundo o estudo, 6 em cada 10 internautas receberam as fake news pelo WhatsApp. O Facebook é a segunda plataforma com maior propagação de notícias falsas, com 5 em cada 10 internautas recebendo fake news pela rede social.

Ao menos $73 \%$ dos brasileiros acreditaram em alguma fake news, seguidos por 65\% dos americanos e 59\% dos italianos. Entre os entrevistados, $80 \%$ disseram que gostariam de receber informações corrigidas por verificadores de fatos. No entanto, 57\% alegaram não terem visto nenhuma correção ou sinal de alerta sobre conteúdo falso ou enganoso no Facebook ${ }^{4}$. (Site UOL, 2020)
\end{abstract}

Além disso, mesmo em contextos acadêmicos é possível encontrar alunos de graduação de cursos de áreas da Ciência acreditando em notícias de conteúdo falso ou duvidoso. É preciso que se faça um trabalho de educação de jovens para que estes possam ter discernimento para distinguir o falso do verdadeiro. Assim, as Fake News são um tema da educação e ensino.

Além disso é necessário que se promova uma visão crítica sobre as mídias e sua influência na formação e propagação de ideias e informações. Para Foer (2018, p. 17) "As empresas já alcançaram o feito de alterar a evolução humana. Todos já viramos um pouco

\footnotetext{
${ }^{4}$ Matéria disponível em: https://www.uol.com.br/tilt/noticias/redacao/2020/05/04/estudo-110-milhoes-debrasileiros-acreditam-em-noticias-falsas-sobre-covid.htm
} 
ciborgues. O celular funciona como uma extensão da nossa memória, terceirizamos funções básicas mentais [...]."

Diante deste panorama geral, o que podemos fazer para mudar este contexto? Como identificar uma Fake News de ciência, a Fake Science? Que notícias têm sido veiculadas na Web e redes sociais sobre Ciência? Como utilizar uma Fake Science para problematizar aulas de Ciências? Que características têm uma Fake Science? Essas são algumas questões norteadoras de pesquisas que temos conduzido nestes últimos anos.

\section{Metodologia de análise da Fake Science}

Incialmente realizamos leituras sobre os temas Fake News, Pós-verdade, notícias falsas de ciências, pseudociência, entre outros. Tendo em mente os pressupostos teóricos, selecionamos Fake Science que chegaram ao nosso conhecimento via aplicativo WhatsApp e que tinham indícios de notícias falsas. Para compor essa amostra solicitamos que os colegas de grupo de pesquisa nos enviassem toda e qualquer mensagem que pudesse se enquadrar como notícia falsa de ciências. Esta etapa de constituição da amostra nem sempre é fácil, pois dependemos que algum grupo ou pessoa de nossa relação mais próxima compartilhe conosco este tipo de mensagem.

Tendo disponível algumas Fake Science (apresentaremos aqui quatro deles) iniciamos o processo de transcrição, dissecação e comparação dos elementos presentes nestas mensagens, na perspectiva de encontrar padrões que se repetiam, que denominamos de indicadores. Para encontrar os indicadores utilizamos as proposições da Análise do discurso, apontadas por Gill (2002), que apresenta a prática da análise do discurso. Para esta autora "Os analistas do discurso, ao mesmo tempo em que examinam a maneira como a linguagem é empregada, devem também estar sensíveis àquilo que não é dito - aos silêncios" (GILL, 2002, p. 255).

Neste estudo o assunto dos vídeos está relacionado com a pandemia do coronavírus, pois foi o assunto mais compartilhado no ano de 2020 pela mídia em geral.

De modo resumido o processo está descrito abaixo:

1 Processo de transcrição: transcrição das falas do locutor e transformação do áudio em texto, incluindo expressões corporais e imagens. Utilizamos na transcrição o símbolo (+) para indicar pausa. Esse processo auxilia na compreensão e facilita a realização da próxima etapa;

2 Processo de dissecação: separação de todas as frases e expressões do locutor que possam indicar padrões repetitivos do discurso, que nos levem à construção de indicadores que compõem o gênero Fake Science. Neste contexto importa tanto a fala quando as expressões faciais, da voz, corporal e outros elementos utilizados no vídeo;

3 Processo de comparação: comparação de todos os vídeos para apontamento das semelhanças, diferenças e estabelecimento de elementos padrões dos vídeos, indicando quais os elementos constituintes de uma notícia falsa e como estes elementos podem levar o público a acreditar na informação. Nesta etapa chegamos à alguns indicadores, que caracterizam uma notícia/informação falsa sobre Ciência. 


\section{Resultados}

\section{Análise dos vídeos}

Foram analisados quatros vídeos relacionados com a COVID-19, nos quais os interlocutores apresentam uma solução para a cura ou prevenção do vírus SARS-Cov-19. Dessa maneira, fizemos os processos de transcrição, dissecação e, por fim, apontamos as semelhanças e diferenças entre os vídeos analisados. Neste artigo apresentaremos os resumos dos vídeos, já que o conteúdo completo das transcrições e análises é demasiado longo.

1. Identificação dos vídeos

\section{Vídeo 1}

Locutor (a): Lila Reis

Título: Chá de abacate com hortelã cura coronavírus

Tempo do vídeo: 4 min e $15 \mathrm{~s}$

Ano de publicação: 2020

Local de acesso: Vídeo recebido via WhatsApp

Resumo: A cristã Lila Reis informa que teve uma revelação com a Nossa Senhora do Carmo, em que dizia que o mundo iria cair em decadência e contaminar todo mundo, que muitas pessoas iriam morrer, e apenas uma única receita de chá poderá curar esse vírus. Segundo ela, a grande preocupação da Nossa Senhora é de as pessoas não acreditarem nela. Com toda tristeza, após ouvir a notícia, Lila diz que sente a necessidade de fazer alguma coisa para divulgar esse chá. Dessa forma, recitou a receita do chá de abacate.

\section{Vídeo 2}

Locutor (a): George Gustavo

Título: Álcool gel não mata coronavírus

Tempo do vídeo: 4 min e $25 \mathrm{~s}$

Ano de publicação: 2020

Local de acesso: Vídeo recebido via WhatsApp

Resumo: O George Gustavo se diz um químico autodidata desde o ano de 1995, que já trabalhou em várias indústrias químicas e teve também a sua própria indústria. Diz que álcool gel não é eficaz contra coronavírus, então explica o motivo da ineficácia. Recomenda a utilização do vinagre, ao invés do álcool, pois a vinagre é ácido, por isso é mais eficaz. Comenta que as indústrias vendem álcool gel só por ser mais lucrativo do que vinagre, pois o vinagre tem custo mais baixo.

\section{Vídeo 3}

Locutor (a): Isabel Teixeira

Título: Curar coronavírus antes de se instalar no pulmão

Tempo do vídeo: 6 min e 17s

Ano de publicação: 2020

Local de acesso: Vídeo recebido via WhatsApp 
Resumo: A Isabel Teixeira fala que, a pedido de um amigo, ela deveria gravar o vídeo, porque ela já ajudou quatro famílias que foram infectados por coronavírus e todas estão curadas. De acordo com a filha dela, que é uma enfermeira da Flórida (EUA), Isabel diz que, caso se sinta alguns sintomas do coronavírus é preciso seguir alguns passos todos os dias, até se sentir melhor. Comenta que deve lavar o nariz e gargarejar com água quente, sal e limão. Tomar, a cada quinze minutos, um copo de água quente com limão e, nos próximos quinze minutos, tomar o chá de gengibre. Além disso, é necessário tomar vitamina $C$, zinco e tomar sol. Não comer nada que contenha açúcar, comidas industrializadas e leite, porque tudo isso auxilia na fermentação e propagação de qualquer doença. Se sentir falta de ar e tosse, inalar eucalipto com água e dormir com umidificador ou uma panela com água fervente.

\author{
Vídeo/áudio 4 \\ Locutor (a): Antoninho Piloto \\ Título: Inhame, maçã e água de coco curam coronavírus \\ Tempo do vídeo/áudio: 2 min e 46s \\ Ano de publicação: 2020 \\ Local de acesso: Vídeo/áudio recebido via WhatsApp
}

Resumo: Antoninho Piloto relata que o sogro dele é do grupo de risco, pois tem muitos problemas em órgãos como coração, pulmão, rins e foi infectado por coronavírus. Felizmente foi tratado por um médico do estado do Mato Grosso, que é conhecido do filho do Antoninho. O locutor repassou a receita do médico constituída por inhame, maçã e água de coco. Depois bater no liquidificador os ingredientes, deve-se ingerir uma vez ao dia.

\title{
2. Os principais elementos que apareceram nos vídeos
}

No quadro 1 apresentamos alguns elementos presentes nos vídeos analisados. Estes elementos nos dão indicadores das características deste tipo de informação, a Fake Science. Os indicadores são construídos a partir da análise do material (no caso, vídeos). Para sua construção é necessário a audição e leitura do material várias vezes, de modo que se possa codificar o discurso, criando categorias de interesse e atribuindo uma denominação para cada informação/ação que acontece no discurso proferido. Inicialmente há uma procura por um padrão de dados, que nos leva a identificar tanto a variabilidade (diferenças entre as narrativas), quanto a sua consistência discursiva. Posteriormente, o foco se dá na identificação da função da narrativa no discurso. (GILL, 2002). Assim, os indicadores vão se constituído no decorrer na análise, permanecendo aqueles que se adequam ao objetivo do estudo, no nosso caso, encontrar elementos no discurso que podem identificar uma notícia falsa de ciência, assim como os elementos que podem levar as pessoas a acreditarem em tais notícias.

A partir do resumo apresentado no quadro 1, podemos dizer que os indicadores que se repetem nos vídeos são: credibilidade, afetividade, informação verdadeira, informação falsa, pedido para compartilhar, intimidade, solução de problema, apelo, apresentação, despedida, receita e religiosidade. Estes indicadores são aqueles que, a partir da comparação entre os vídeos, nos levam à caracterização de uma notícia falsa, pois há entre 
eles um "certo padrão discursivo", o que nos encaminha a refletir sobre esse gênero do discurso, considerando os estudos de gênero de Bakhtin (2016).

Quadro 1: Elementos que apresentaram nos vídeos

\begin{tabular}{|l|l|}
\hline Indicadores/Elementos & Vídeos \\
\hline Credibilidade & Em todos os vídeos \\
\hline Afetividade & Em todos os vídeos \\
\hline Informação verdadeira & Em todos os vídeos \\
\hline Informação falsa & Em todos os vídeos \\
\hline Pedido para compartilhar & Em todos os vídeos \\
\hline Intimidade & Em todos os vídeos \\
\hline Solução de problema & Vídeo 1 , vídeo 2 e vídeo 4 \\
\hline Apelo & Em todos os vídeos \\
\hline Apresentação & Em todos os vídeos \\
\hline Despedida & Em todos os vídeos \\
\hline Receita & Em todos os vídeos \\
\hline Sentimento de culpado & Vídeo 1 \\
\hline Culpando outros & Vídeo 2 \\
\hline Assustado (a) & Vídeo 1 \\
\hline Religiosidade & Vídeo 1, vídeo 3 e vídeo 4 \\
\hline Convite & Vídeo 1 \\
\hline Divulgação & Vídeo 1 e vídeo 3 \\
\hline Sensacionalismo & Vídeo 3 e vídeo 4 \\
\hline Recomendação & Vídeo 3 \\
\hline Crença popular & Vídeo 2 e vídeo 3 \\
\hline Exemplos & Vídeo 2 e vídeo 3 \\
\hline Objetivo & Vídeo 2 \\
\hline Conselho & Vídeo 2 \\
\hline Objeto de laboratório & Vídeo 2 \\
\hline Nomenclatura científica & Vídeo 2 \\
\hline Ameaça & Vídeo 2 \\
\hline
\end{tabular}

Então, para a informação tornar-se verdadeira é necessário a confiança do público, entretanto, o locutor geralmente apresenta o elemento de credibilidade, quando indica uma pessoa experiente sobre o assunto, que podemos chamar de "autoridade". No caso do vídeo 1, a receita foi revelada por uma "Santa", dessa forma conquistará algum público religioso. O locutor do vídeo 2 se autoproclama como um químico autodidata, que já trabalhou em várias indústrias, o que Ihe dá credibilidade para falar sobre determinados assuntos. Já o vídeo 3 e 4 mencionam uma enfermeira e um médico, respectivamente. Ambos dizem que as receitas são eficazes, pois já curaram muitas pessoas. Para estabelecer a confiança, em geral, é demonstrado, ao mesmo tempo, a afetividade; intimidade; informação verdadeira; religiosidade e credibilidade. Estas ocorrem principalmente nas partes inicial e final dos vídeos, por exemplo: "olá meus amigos", "desejo uma bênção" e "um abraço para todos". Esse tipo de discurso aproxima a audiência, trazendo mais emoção e afeto para público. 
Mas, não basta se expressar apenas a confiança, o conteúdo da informação também deve ser mais persuasivo e chamativo. A respeito disso, implica um pouco de informação verdadeira e sensacionalismo, ocasionando em maior atenção do público.

A informação fundamental nesses vídeos trata-se da receita, é o momento de expor a informação verdadeira e falsa. Em geral, as receitas são simples e conhecidas popularmente saudáveis, por exemplo: tomar sol para adquirir vitamina $D$, vinagre e limão tem função de desinfecção, chá de gengibre faz bem e o limão "queima" a pele se expor ao sol.

Por fim, o objetivo de Fake News é divulgar ao maior número de pessoas possível e de forma rápida. Dessa forma, o elemento mais utilizado nos vídeos é o "apelo", ou seja, o pedido para compartilhar. Assim, como por exemplo: vídeo 1: "[...] gente por favor (+) mundo (+) faça isso (+) traduza esse chá em todas as línguas (+) pra que todos possam ser salvos salvem sua família seus amigos acreditem nisso [...]" ou no vídeo 2: "[...] por favor retransmite isso pra todo mundo (+) à maior quantidade possível de pessoas [...]".

\section{Relação das linguagens não-verbais com Fake News}

De acordo com Prochet (2010, p. 48) "A comunicação não-verbal nos auxilia para que os sentimentos e os pensamentos sejam expressos, revelando também a coerência entre a intenção e o discurso." Provavelmente, as expressões facial, da voz e corporal influenciam na confiança da notícia. Estas expressões corporais também fazem parte de persuasão. Nos vídeos fica evidente que os locutores expressavam de uma forma séria e confiante o que estão falando. No momento em que os locutores demonstram afetividade e compartilhamento do vídeo, as expressões, em geral, são mais calmas, transparecendo tristeza ou felicidade, trazendo uma sensação que é uma pessoa boa e gentil. Por exemplo, no vídeo 2, o locutor é sério ao longo do vídeo, trazendo uma sensação de estar protestando, dizendo que álcool gel não funciona, e é vendido só para lucrar mais na venda. No caso do vídeo/áudio 4, o locutor transmite, pela voz, a sensação de estar sério e confiante.

Além disso, a linguagem não verbal também serve para destacar e explicar certas mensagens como, por exemplo, no vídeo 3, em que a locutora se utiliza de gestos (com os dedos) para demonstrar a "quantidade" de água ou movimenta a cabeça negativamente quando está dizendo "[...] sem açúcar (+) nada de açúcar [...]", para afirmar que não pode colocar açúcar no chá de gengibre. Ainda ela movimenta a cabeça afirmativamente quando fala: "[...] oh! água e gengibre ferveu bem $(+)$ toma $(+)$ então alterne a cada quinze minutos [...].", para indicar que é correto fazer dessa forma.

4. Os fatores possíveis que fazem o público acreditar no vídeo

Após fazer dissecação dos vídeos podemos destacar alguns fatores possíveis que fazem o público acreditar no vídeo

\section{Vídeo 1}

1. Usa, em nome da Nossa Senhora do Carmo a fé e a religiosidade;

2. Receita simples e "milagrosa" (chá faz parte da cultura popular);

3. Plantas são benéficas a nossa saúde, e tomar chá faz bem;

4. Não importa a religião, qualquer pessoa poderá utilizar a receita (o chá soluciona os problemas mesmo para quem não tem fé); 
5. Lila expressa que é uma pessoa bondosa e temente à Deus, isso provoca credibilidade em pessoas que seguem alguma religião;

6. Se Lila quer ajudar, "eu" também posso ajudar alguém repassando a mensagem;

7. Aproximação com o interlocutor, por meio das expressões visuais do falante;

8. A grande preocupação das pessoas com a saúde em geral, independente da pandemia.

\section{Vídeo 2}

1. George é um químico que já trabalhou em várias indústrias;

2. Utiliza nomenclaturas científicas e linguagem mais técnica, dificultando o entendimento de um público leigo em ciências, portanto traz a ideia de ser um profissional respeitável sobre o assunto;

3. Contém algumas informações verdadeiras para dar fortalecimento e credibilidade;

4. Receita simples, de fácil acesso (no caso é vinagre);

5. Critica a mídia e as empresas, fortalecendo ideias de pessoas que apoiam a mesma perspectiva;

6. Diz que os químicos "decentes e honestos" vão apoiá-lo (conclama apoio de uma classe);

7. Cita exemplos da China e da Coreia, dizendo que as pessoas de lá utilizam álcool gel e mesmo assim são contaminados;

8. Expressões faciais, voz e corporal, nos fazem sentir que o locutor é confiável.

\section{Vídeo 3}

1. A locutora já ajudou quatro famílias que estavam infectados por coronavírus (uma pessoa bondosa);

2. A filha é uma enfermeira que trabalha na Flórida (EUA). Em geral, os brasileiros associam os EUA como um país mais desenvolvido, onde as tecnologias e a educação são muito melhores do que no Brasil;

3. Contém informação verdadeira, como os primeiros sintomas de coronavírus é a perda de olfato e paladar;

4. Crença popular ou senso comum como chá de gengibre, água quente, vitamina $C$, vitamina D para curar uma gripe;

5. Pedido de compartilhamento, trazendo ao público o sentimento de estar fazendo um ato de bondade por compartilhar o vídeo;

6. Receita simples e econômica;

7. Expressão séria, trazendo ao público a sensação de que é um assunto importante e sério.

Vídeo 4

1. O sogro do Antoninho teve COVID-19 confirmado, mas se recuperou depois de dois dias;

2. A receita provém de um médico, que faz trata a COVID-19 e o município não apresenta mais casos;

3. Receita simples e saudável;

4. Pedido de compartilhamento. 
Ao comparar os vídeos podemos destacar sete principais fatores que trazem credibilidade ao público: autoridade, afetividade, receitas simples, pedido para compartilhar, linguagem não-verbal, informação verdadeira e preocupação em relação a saúde.

\section{Discussão dos resultados}

Ao relacionar os vídeos com a literatura, foi possível comparar alguns principais fatores podem fazer o público acreditar nas informações. Os locutores utilizam o nome de uma autoridade como médico, químico ou uma Santa, para trazer a sensação da credibilidade. Este tipo de recurso de persuasão também acontece em matérias jornalísticas. Segundo Goldacre (2013, p. 299 - 300): "Existem muitas maneiras como os jornalistas podem enganar um leitor por meio da ciência: eles podem escolher as evidências ou arejar as estatísticas ou podem colocar a histeria e a emoção diante das afirmações frias e neutras feitas pelas figuras de autoridade."

Conforme o D'Ancona (2018, p. 66 - 67): "[...] apresentar a uma pessoa que acredita numa teoria da conspiração uma evidência que seja de que ela não tem fundamento pode muitas vezes reforçar sua crença [...]. Sua força popular depende não de evidência, mas do sentimento."

No vídeo 2, o locutor emprega palavras técnicas, pouco usuais no cotidiano das pessoas e isso reforça o poder de autoridade do locutor, podendo induzir à confiança da mensagem. Do mesmo modo, no vídeo 1, a autoridade é a Nossa Senhora do Carmo, por meio de uma "revelação", estando deste modo a informação ligada a fé e, portanto, sem possibilidade de comprovação empírica. Neste caso, a ideia é a fé e a afirmação de alguém que recebeu uma informação divina. Por isso, de acordo com o Pilati (2018), a religião e crença são um sistema de crença infalseável.

Além disso, como os vídeos tratam da COVID-19, nós, como seres humanos, nos preocupamos com vida e a morte. Consequentemente, o receio sobre saúde ganha maior importância, e a chance de sermos persuadidos por receitas simples aumenta em momentos de instabilidade emocional causada por uma pandemia. Este fato também se evidencia nas notícias verídicas, onde, de acordo com Goldacre (2013, p. 254): "Mais da metade de toda a cobertura sobre ciência em um jornal refere-se à saúde, porque histórias sobre o que irá nos matar ou curar são muito motivadoras [...]".

Diante disso, os elementos identificados nos vídeos se assemelham com os elementos presentes em mensagens escritas (já analisadas por esse grupo de pesquisa), no qual se destaca os indicadores de afetividade, credibilidade, cultural, falsidade, verdade e persuasão. Entretanto há uma diferença, ou seja, nos vídeos temos também a linguagem não-verbal, que implica também em conquistar um maior público. De acordo com Silva et al. (2000), a linguagem corporal é complexa, ocorre à margem do nosso controle e tem a função de expressar sentimentos, emoções, reações e transmitir mensagens. Dependendo do contexto e cultura, pode manifestar-se de forma natural, intuitiva e continua.

\section{Considerações Finais}

Os elementos padrões (indicadores) estabelecidos tanto nas mensagens escritas quanto nos vídeos são semelhantes como mencionamos anteriormente. De modo geral, o que 
cativa confiança do público em um vídeo Fake Science é uma autoridade como médico ou uma pessoa que entende (supostamente) do assunto (como é o caso do vídeo 2), ou uma entidade que infalseável se baseia à nossa crença (assim como no vídeo 1), a afetividade em relação do carisma, receitas simples e acessível, pedido para compartilhar, linguagem nãoverbal e preocupação em relação a saúde.

Contudo, podemos afirmar que o compartilhamento das mensagens ou vídeos, está conectado mais com as nossas emoções do que a própria razão, relacionando diretamente com o efeito da Pós-verdade. Por isso, a importância de a sociedade ter mais acesso à "cultura científica", podendo então tornar-se um cidadão crítico, e com melhor condição para fazer escolhas do que lê ou assiste.

Segundo Barack (2017) apud D' Ancona 2018, p. 52, "Nós nos tornamos tão seguros em nossas bolhas que começamos a aceitar apenas informações, verdadeiras ou não, que correspondem às nossas opiniões, em vez de baseamos nossas opiniões nas evidências que estão por aí." Diante disso, o LIM (Letramento Informacional e Midiático) é uma possibilidade de trabalho em sala de aula e que pode levar os estudantes a saírem de suas "bolhas virtuais", ampliando a sua visão de mundo e dos limites da informação. Pois, desenvolver atividades de análise e discussão de notícias falsas sobre ciência permite que os estudantes compreendam e analisem corretamente as informações que recebem nas redes sociais e nas diversas formas de comunicação da sociedade contemporânea. Este tipo de trabalho exige uma análise de interpretação de textos e/ou vídeos e até mesmo de imagens estáticas seguida de um debate crítico a respeito do que é uma Fake Science.

Além disso é importante que as pessoas tenham uma certa dose de ceticismo, pois para Sagan (2006, p. 81), "O ceticismo deve ser um componente do conjunto de ferramentas do explorador, senão perderemos o rumo. Já existe maravilhas demais lá fora, sem que precisemos inventar algumas."

Neste contexto está a função do professor de Ciências no processo de interpretar a mídia e suas mensagens. Função esta nem sempre considerada como atribuição do professor de Ciências, mas presente em outra área, isto é, na Língua Portuguesa. Assim há que se considerar a tarefa de levar para a sala de aula a discussão sobre notícias falsas sobre a Ciência como parte da atribuição do professor de Ciências, considerando os amplos aspectos da informação, que incluem não apenas o conteúdo da informação (verdadeiro ou não), mas uma discussão mais ampla da mídia, de percepções equivocadas da ciência e negacionismo da ciência, da historiografia da ciência, do efeito da Pós-verdade e outros pontos e assuntos de interface entre a mídia e a educação.

Para finalizar nos reportamos à alguns dados estatísticos, como os apresentados em pesquisa "TIC Kids", publicada pelo Comitê Gestor da Internet no Brasil ${ }^{5}$. Este estudo aponta que no Brasil cerca de 24,3 milhões de crianças e adolescentes são usuários de internet (dado de 2016) e, dentre aos usuários (as), temos 31\% com idade entre 11 e 17 anos. Estes jovens afirmam (nesta pesquisa) que não são capazes de verificar se uma informação encontrada ali está correta. Assim, algumas ferramentas e atividades educacionais devem ser incorporadas ao fazer escolar, trazendo para a sala de aula discussões sobre a mídia e suas consequências diretas e indiretas para o conhecimento científico.

\footnotetext{
${ }^{5}$ Pesquisa disponível em: https://cetic.br/media/docs/publicacoes/2/TIC_KIDS_ONLINE_2016_LivroEletronico.pdf
} 


\section{Referências}

BAKHTIN, M. Os gêneros do discurso. In: Bezerra, P. (Ed.). Os gêneros do discurso, p. 11 - 70. São Paulo: Editora 34, 2016.

BITTENCOURT, R. L. de; FERREIRA, D. A; ROCHA, A. M. M. Letramento Midiático: Um Olhar Além da sala de Aula. Revista Linguagem, Ensino e Educação - Lendu, v. 4, n. 1, 2016.

D'ANCONA, M. PÓS-VERDADE: A nova Guerra contra os fatos em tempos de FAKE NEWS. Barueri: Fora, 2018.

FOER, F. O mundo não pensa. Tradução: Debora Fleck. Rio de Janeiro: Leya, 2018, 236 p.

GILL, R. Análise do discurso. In: Bauer, M. W.; Gaskell, G. Pesquisa Qualitativa com texto, imagem e som: um manual prático, p. 244 - 270, 4ª ed. Petrópolis: Editora Vozes, 2002.

GOLDAGRE, B. Ciência Picareta. Tradução: Renato Rezende. 1 ed. Rio de Janeiro: Civilização Brasileira, 2013. 378 p.

GOMES, S. F.; Penna, J. C. B. O; ARROIO, A. Fake News Científicas: Percepção, Persuasão e Letramento. Ciência \& Educação, n. 26, 2020, p. 1-13.

HOPF, H.; KRIEF, A.; MEHTA, G.; MATLIN, S. A. Fake science and the knowledge crisis: ignorance can be fatal. The Royal Society Publishing. Maio de 2019. Disponível em: https://royalsocietypublishing.org/doi/10.1098/rsos.190161. Acesso em: 05 mai. 2021.

PILATI, R. Ciência e pseudociência: por que acreditamos apenas naquilo em que queremos acreditar. São Paulo: Contexto, 2018. 160 p.

PROCHET, T. C. Capacitação em comunicação não-verbal: um caminho para ações de cuidado efetivo/afetivo ao idoso. Tese de Doutorado. Universidade de São Paulo. 2010.

RIBEIRO, L. A. M.; GASQUE, K. C. G. D. Letramento Informacional e Midiático para professores do século XXI. Em Questão, v. 21, n. 2, p. 203-221, 2015.

SAGAN, C. O Mundo Assombrado pelos Demônios: a ciência vista como uma vela no escuro. Tradução: Eichemberg. 1 ed. São Paulo: Companhia das Letras, 2006. 508 p.

SCHULZ, P. Falsa Ciência e Pós-Ciência? Revista Com Ciência. Labjor. 2018. Disponível em: http://www.comciencia.br/falsa-ciencia-e-pos-ciencia. Acesso em: 10 mai. 2019.

SILVA, L. M. G da; BRASIL, V. V.; GUIMARÃES, H.C.Q.C.P; SAVONITTI, B.H.R. de A.; SILVA, M. J. $P$ da. Comunicação não-verbal: reflexões acerca da linguagem corporal. Revista LatinoAmericana de Enfermagem, n. 8, 2000, p. 52-58.

TIC Kids Online Brasil. Pesquisa sobre o uso da internet por crianças e adolescentes no Brasil 2016. Núcleo de Informação e Coordenação do Ponto BR. São Paulo: Comitê Gestor da Internet no Brasil, 2017. Disponível em:

https://cetic.br/media/docs/publicacoes/2/TIC_KIDS_ONLINE_2016_LivroEletronico.pdf. Acesso em: 03 mai. 2020. 